\title{
Scientific Progress: Knowledge versus Understanding
}

\author{
Finnur Dellsén
}

Penultimate draft - forthcoming in Studies in History and Philospophy of Science

\begin{abstract}
What is scientific progress? On Alexander Bird's epistemic account of scientific progress, an episode in science is progressive precisely when there is more scientific knowledge at the end of the episode than at the beginning. Using Bird's epistemic account as a foil, this paper develops an alternative understanding-based account on which an episode in science is progressive precisely when scientists grasp how to correctly explain or predict more aspects of the world at the end of the episode than at the beginning. This account is shown to be superior to the epistemic account by examining cases in which knowledge and understanding come apart. In these cases, it is argued that scientific progress matches increases in scientific understanding rather than accumulations of knowledge. In addition, considerations having to do with minimalist idealizations, pragmatic virtues, and epistemic value all favor this understanding-based account over its epistemic counterpart.
\end{abstract}

\section{Introduction}

Although it is nearly uncontroversial that science makes progress of some sort or other, it is far from uncontroversial what scientific progress consists in. Historically, scientific progress has often been associated with advances in scientific knowledge, e.g. 
by Francis Bacon (1620/1900), George Sarton (1927), and William Bragg (1936).

More recently, Alexander Bird (2007, 2008, forthcoming) has defended an influential version of this view, the epistemic account, according to which an episode in science constitutes progress precisely when there is more scientific knowledge at the end of the episode than at the beginning. ${ }^{1}$ Using Bird's epistemic account as a foil, this paper develops an understanding-based account of scientific progress and argues that it is superior to the epistemic account. On this view, an episode in science is progressive precisely when scientists grasp how to correctly explain or predict more aspects of the world at the end of the episode than at the beginning. I will refer to this as the noetic account of scientific progress. ${ }^{2,3}$

My arguments for preferring the noetic account over the epistemic account are primarily concerned with two classes of cases in which the accounts give conflicting verdicts about whether scientific progress has been made. On the one hand, I locate a class of cases in which there is an increase in scientific understanding even though no

${ }^{1}$ Other contemporary proponents of the epistemic account include Barnes (1991) and Cohen (1980).

2 'Noetic' as in the Greek 'nous', which is often translated into English as 'understanding'.

3 Those that come closest to defending something like the noetic account of scientific progress in the contemporary literature are Sorin Bangu (2015) and Angela Potochnik (2015). Bangu argues that Bird's epistemic account should be supplemented with the suggestion that progress can be made by unifying scientific theories, where such unification constitutes increased understanding on his view. Relatedly, Potochnik suggests that one aim of science consists in giving idealized explanations that contribute to understanding of the explained phenomena. Although Potochnik is concerned with the aim of science as opposed to scientific progress, we shall see (in section 2) that there is a straightforward way in which views about the aim of science translate into views about scientific progress.

I lack the space here to discuss Bangu's and Potochnik's views in detail. Suffice it to say that both views differ in key respects from the account defended in this paper: First of all, both of these views employ conceptions of understanding that differ substantially from the one I will use in this paper (see section 1). Bangu's and Potochnik's views are also considerably less ambitious, in effect claiming only that increasing understanding is one way for science to make progress. Indeed, Bangu and Potochnik do not argue that the kind of understanding they are interested in does not reduce to scientific knowledge, in which case their views would be entirely compatible with the epistemic view. Finally, the motivations for these views are very different from the arguments given in this paper. 
new theories or phenomena become known in the process. On the other hand, I also locate a class of cases in which knowledge is accumulated but there is no increase in scientific understanding. In both cases, I argue that scientific progress matches increases in scientific understanding rather than accumulations of knowledge. In addition, considerations having to do with minimalist idealizations, pragmatic virtues, and epistemic value all favor the noetic account over its epistemic counterpart.

The plan of the paper is as follows. Section 1 clarifies the issue at hand and briefly surveys accounts of scientific progress in the contemporary literature. Section 2 spells out the noetic account by specifying what kind of understanding the noetic account is concerned with and shows how understanding, so conceived, differs from knowledge. Sections 3 and 4 argue that the noetic account is superior to the epistemic account by examining two classes of cases in which the epistemic account and the noetic account offer conflicting verdicts about whether scientific progress has been made. Section 5 responds to concerns that achieving increased understanding is either too easy, or too hard, for it to constitute scientific progress. Section 6 briefly considers some further advantages of the noetic account of scientific progress over the epistemic account. Section 7 is the conclusion.

\section{Scientific Progress}

In general, an episode can be said to be progressive when the state of affairs at the end of the episode is an improvement on the state of affairs at the beginning. However, accounts of scientific progress are not meant to capture all kinds of progress, not even 
all kinds of progress that concern changes in the scientific enterprise. ${ }^{4}$ Rather, accounts of scientific progress concern the kind of cognitive progress that roughly consists in improving the ways in which science represents the world. For example, cognitive progress was made when Einstein's theories of special and general relativity replaced Newtonian mechanics, and also when the latter replaced the mechanical principles developed by Galileo and Descartes. Similarly, cognitive progress was made when Eddington's plum-pudding model of the atom was superseded by Rutherford's planetary-orbit model, which in turn was superseded by Bohr's quantum-mechanical model. Since the sort of progress that I will be discussing in this paper falls quite clearly under cognitive progress, I will not in this paper give a precise definition of 'cognitive progress' or distinguish it from other non-cognitive kinds of progress (in science or elsewhere). Indeed, in what follows I will use the term 'progress' as shorthand for 'cognitive progress'.

It is worth noting that the question of what constitutes scientific progress is closely related to the long-standing debate between scientific realists and anti-realists about the aim of science. Roughly following Bird (2007) and Niiniluoto (2015), this relationship can be described as follows:

(A) $\mathrm{X}$ is the aim of science just in case science makes progress when $\mathrm{X}$ increases or accumulates. ${ }^{5}$

So, on the epistemic account, science aims to give us knowledge of the world, whereas on the noetic account science aims to enable us to understand the world ${ }^{6}$ We could

\footnotetext{
${ }^{4}$ On this point, see Niiniluoto (2015: $\left.§ 2.1\right)$.

5 Those who think science has more than one (cognitive) aim may replace 'the' with 'an' in (A).

${ }^{6}$ Thus, in so far as van Fraassen (1980) is correct to define scientific realism and anti-realism in terms of whether science aims at its theories being true or merely empirically adequate, these accounts amount
} 
supplement (A) by adding that science promotes progress precisely when it promotes the increase or accumulation of $\mathrm{X}$, where $\mathrm{X}$ is the aim of science. ${ }^{7}$ Clearly, promoting scientific progress is itself very valuable, almost as valuable as progress itself. Nevertheless, since nearly anything can promote progress, we must be careful not to confuse scientific progress itself with the promotion of such progress. For example, technological advances, increased funding for scientific research, and hunches about how a problem might be solved, all promote progress in typical cases although they presumably do not themselves constitute (cognitive) scientific progress. So promotion of progress is not necessarily itself progress. We will return to this point in section 5, where I will argue that collecting raw data is sometimes best characterized as promoting (as opposed to constituting) scientific progress.

This paper focuses on two accounts of scientific progress (thus understood), Bird's (2007, 2008, forthcoming) knowledge-based epistemic account and my own understanding-based noetic account. I won't be concerned here, except in a derivative way, with other accounts of scientific progress in the current literature. Of alternative accounts, two are most prominent: the verisimilitudinarian account and the problem-solving

to two distinct realist views of the aim of science. To see this, consider the epistemic account first: Since knowledge is factive, the epistemic account entails that science aims for truth as well as for other components of knowledge (e.g. epistemic justification). Hence the epistemic account amounts to a strongly realist view on van Fraassen's conception of scientific realism. Whether the noetic view also counts as realist will depend on whether understanding, like knowledge, is factive. In section 2, I will suggest that understanding is quasi-factive - roughly in the sense that the explanatorily/predictively essential elements of a theory must be true in order for the theory to provide grounds for understanding. Thus conceived, the noetic account amounts to a moderately realist view of the aim of science. Specifically, the noetic account entails that the aim of science may be satisfied by theories that distort some aspects of reality, e.g. idealizations such as the ideal gas law, provided that the distortions introduced by such theories facilitate explanations and/or predictions (we will return to this issue in section 6). So, while the noetic account holds that science does not merely aim for empirically adequate theories, it also recognizes that the aim of science may be satisfied by theories that are not completely accurate descriptions of reality.

${ }^{7}$ Bird (2007: 83-84) also characterizes the connection between scientific progress and the aim of science in terms of promotion, but in a different way than I do here. More on this in section 5. 
account. According to the verisimilitudinarian account, science makes progress when its theories come closer to the truth, i.e. when their 'verisimilitude' increases (Popper 1963, 1979; Niiniluoto 1980, 2014). The problem-solving account, by contrast, holds that science makes progress by increasing its capacity for solving empirical and conceptual problems in a way that is recognizable by the scientific practitioners themselves (Kuhn 1970; Laudan 1977, 1984). Both of these accounts raise important and mostly distinct issues that cannot be adequately dealt with in this paper. Thus a systematic comparison of these accounts with the noetic account will have to await another occasion.

Although the idea that scientific progress should be associated with understanding is rarely discussed in the literature on scientific progress, ${ }^{8}$ related ideas did surface in discussions of scientific explanations in the latter half of the previous century. In particular, Scriven (1962), Friedman (1974) and Kitcher (1981, 1989) argued that an adequate account of explanation must show how explanations produce

${ }^{8}$ As we will see, Bird (2007: 84) briefly discusses the idea that scientific progress consists in increasing understanding, but takes it to be compatible with his epistemic view (I will argue differently below). Other than Bird, Bangu (2015) and Potochnik (2015) are the only other authors of which I am aware who (explicitly or implicitly) associate scientific progress with scientific understanding in a sense similar to that in which I will be using the term - see footnote 3 .

It may be worth noting, however, that earlier discussions of scientific progress include a proposal by Finocchiaro $(1975,1976)$ to supplement Laudan's problem-solving account of scientific progress with the idea that progress may consist in increasing the intelligibility of the theoretical concepts used in solving scientific problems. Finocchiaro refers to this process as "growth of understanding". However, as I explain in section 2 below, the kind of understanding that I will argue increases as science makes progress is concerned with understanding natural phenomena as opposed to theoretical concepts, and should therefore not be confused with conceptual intelligibility of the kind that interests Finocchiaro. Moreover, the kind of understanding which I argue increases when science makes progress is necessarily based on substantially correct theories - a requirement that Finocchiaro (1975: 126) explicitly eschews, in line with Laudan's problem-solving approach in which scientific progress is wholly dissassociated from external criteria such as truth (more on this in section 3). Thus, at least for the purposes of this paper, Finocchiaro's view counts as a version of the problem-solving account of scientific progress as opposed to understanding-based views such as the noetic account. (I am grateful to an anonymous reviewer for calling my attention to Finocchiario's work on this topic.) 
understanding - a point that Friedman and Kitcher famously took to count in favor of a unificationist account of explanation. ${ }^{9}$ In contrast to Scriven, Friedman and Kitcher, my interest is not with the relationship between understanding and explanation, but with how understanding relates to scientific progress. Although I do take understanding to be closely related to explanation, I will not be presupposing a unificationist account of explanation in what follows, nor will I assume that understanding always involves unification. Indeed, as we shall now see, my conception of understanding is not only broad enough to be compatible with any specific account of explanation, but also allows for understanding to increase by means other than

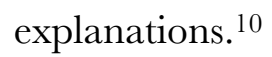

\section{Scientific Understanding}

As advertised above, I will argue that the understanding-based noetic account of scientific progress is superior to the knowledge-based epistemic account. In arguing for this, I assume that it is possible for there to be increases in scientific understanding without accumulations of scientific knowledge, and vice versa. This section outlines a conception of understanding on which this assumption holds. Outlining this

\footnotetext{
${ }^{9}$ For a more recent unificationist account of explanation that particularly emphasizes the role of understanding, see (Schurz and Lambert 1994; Schurz 1999); for detailed criticism of this proposal, see (Gijsbers 2007; 2013). Although the emphasis on understanding in relation to scientific explanation has generally been stronger among those who adopt unificationist theories of explanation, it is worth noting that Wesley Salmon, a long-time proponent of a causal theory of explanation (Salmon 1984), also emphasized the centrality of understanding in thinking about scientific explanations, especially in his later work (e.g., Salmon 1993, 1998: ch. 5). Interestingly, however, Salmon explicitly allowed for the existence of non-causal explanation (and thus non-causal understanding) in his more recent work (e.g., Salmon 1989: 183-184, 1998: 73-78).

${ }^{10}$ For arguments that scientific understanding and explanation can come apart, see (Lipton 2009) and (Gijsbers 2013).
} 
conception also serves to specify in what sense the noetic view takes scientific progress to consist in increasing scientific understanding.

Let me note at the outset, however, that this conception of scientific understanding will not be uncontroversial. Indeed, there are many competing views of the nature of understanding in the current literature, some of which conceive of understanding as a species of knowledge. ${ }^{11}$ While I agree with a number of other authors that knowledge-based conceptions of understanding are inadequate, ${ }^{12} \mathrm{I}$ will not rehearse the arguments for that here. Rather, since my concern here is with the nature of scientific progress as opposed to the nature of understanding per se, I am happy to adopt a stipulative definition of 'scientific understanding' for the purposes of this paper. So, while I do think that my definition is plausible and independently motivated, readers need not agree with it in order to accept my arguments against the epistemic account and in favor of the alternative noetic account.

To a first approximation, the conception of scientific understanding that I will adopt defines understanding in terms of grasping how to correctly explain and predict aspects of a given target. ${ }^{13}$ Four points are worth highlighting in this regard: First,

\footnotetext{
${ }^{11}$ Notable proponents of views of this sort include Kitcher (2002), Lipton (2004), Brogaard (2005), and Grimm (2006, 2014). In fact, Bird himself states that to understand something is "to know what causes, processes or laws brought it about." (Bird 2007: 84) We will return to this comment below.

12 Understanding has been argued to differ from knowledge in various ways, e.g. by being transparent (Zagzebski 2001), by being immune to Gettier problems (Kvanvig 2003, 2009; Pritchard 2009, 2010), and by not requiring exact truth (Elgin 2007, 2009a, 2009b; Riggs 2009; Mizrahi 2012; Strevens 2013). I myself argue elsewhere that understanding differs from knowledge in not requiring epistemic justification or belief [Author Paper].

${ }^{13}$ It is common for theorists to distinguish between two different kinds of understanding, viz. objectual understanding and understanding-why. Objectual understanding is the kind of understanding that is grammatically followed by an object, as in "She understands economic depressions." By contrast, understanding-why is the kind of understanding that is typically expressed using a why-clause, as in "She understand why economic depressions happen." As my discussion should make clear, I will be concerned with objectual understanding as opposed to understanding-why. (For discussions on objectual understanding versus understanding-why, see Kvanvig (2009) and Khalifa (2013a).)
} 
scientific understanding is clearly a matter of degree. ${ }^{14}$ On the conception of understanding that I favor, a complete understanding of a given target would require one to grasp how to correctly explain and predict every aspect of the target. However, one can approach a complete understanding by grasping how to correctly explain or predict some aspects of the target in question. In that case, one has partial understanding of the target. Since my concern in this paper is primarily with increases in scientific understanding, which may come about even when no target is completely understood, I will mostly be concerned with partial as opposed to complete understanding.

A second point worth highlighting is that while it is standard to associate understanding with explanation, it is less common to associate understanding with prediction. For example, on Michael Strevens's 'simple view' of understanding, "[a]n individual has scientific understanding of a phenomenon just in case they grasp a correct scientific explanation of that phenomenon." (Strevens 2013: 510) However, it seems to me that this over-intellectualizes the nature of the scientific understanding. In particular, a scientist who makes correct predictions about something under various conditions without also realizing how to explain it does seem to have at least some understanding of the phenomenon in question. For example, an agent has some understanding of the weather on a given day if she realizes how to correctly predict changes in the weather given a variety of different readings on her barometer. ${ }^{15}$ Thus,

\footnotetext{
14 The gradability of understanding is emphasized by many authors, including Kvanvig (2003, 2009), Khalifa (2013b), Wilkenfeld (2013), and Kelp (forthcoming).

15 Admittedly, she would not possess a complete understanding of the weather - only a partial understanding. A complete understanding of the weather would undoubtedly also require a grasp of how to explain the relevant changes in the weather. It is also worth noting that I am not claiming that a single correct prediction of a storm would constitute even a partial understanding of the weather. Instead, what is claimed here is that grasping how to correctly predict storms given a variety of different barometer readings would constitute a partial understanding of the weather. More generally, what is claimed here is not that a single correct prediction would constitute partial understanding of a target, but that partial understanding can consist in grasping how to predict some aspect of a target under a
} 
in so far as explanation and prediction can come apart, ${ }^{16} \mathrm{I}$ favor a conception of understanding on which grasping how to correctly predict some aspect of a given target in the right sort of circumstances counts as partially understanding it.

A third point is that I will be following Strevens (2013: 512-513) in saying that an explanation can be correct even though it appeals to theories that are strictly speaking false, e.g. idealizations and simplifications, provided that those theories help identify the explanatorily relevant factors on which the explanandum depends. Of course, not all false theories can ground correct explanations; the distortions or simplifications made by such a theory must be genuinely irrelevant to the explanandum. For example, the ideal gas model provides for a greatly simplified account of some real gases by ignoring (among other things) collisions between molecules. However, since these collisions do not make a difference to many explananda, there is a class of explanations based on the ideal gas model that have the kind of accuracy that is required for scientific understanding. For this reason, I agree with authors such as Elgin (2007, 2009a, 2009b), Mizrahi (2012), and Strevens (2013) that understanding is quasi-factive rather than factive. ${ }^{17}$

A final point about my conception of understanding worth elaborating on concerns the psychological element involved in understanding (analogous to the psychological attitude of belief involved in knowledge) - what I have, following several

variety of different circumstances. (I will elaborate further on this point below when discussing the nature of grasping.)

${ }^{16}$ Hempel and Oppenheim (1948) famously proposed that explanation and prediction differ only with regard to whether the predicted or explained phenomenon had already been observed at the time. This 'symmetry thesis' has now been abandoned in mainstream philosophy of science, and for good reason. However, as Douglas (2009) argues, there might nevertheless be a quite tight connection between explanation and prediction in science.

17 The term 'quasi-factive' is due to Mizrahi (2012: passim). 
other authors, referred to as 'grasping'. ${ }^{18}$ Without a psychological element of this sort, understanding would not be a cognitive attitude, in which case increased understanding would be ineligible as an explication of cognitive progress in science (see section 1). But what, then, is grasping? This question does not admit of an easy answer. ${ }^{19}$ However, for the purposes of this paper, I will follow Grimm (2011) in taking grasping to be (at least extensionally equivalent to) "an ability not just to register how things are, but also an ability to anticipate how certain elements of the system would behave, were other elements different" (Grimm, 2011: 89).20 Thus, grasping how to explain or predict something involves not only a mental representation of a particular explanation or prediction, but also an associated ability to anticipate how to explain or predict the behavior of the same thing in somewhat different circumstances. Intuitively, this latter ability distinguishes someone who truly understands something from someone who has merely memorized the steps in a correct explanation or prediction of its behavior in a particular instance. ${ }^{21}$

Keeping these four points in mind, I offer the following definition of scientific understanding:

(U) An agent has partial scientific understanding of a given target just in case she grasps how to correctly explain and/or predict some aspects of the target in the right sort of circumstances.

\footnotetext{
${ }^{18}$ See, for example, Kvanvig (2003, 2009), Grimm (2006, 2014), Khalifa (2013c), and Strevens (2013).

${ }^{19}$ Indeed, as Strevens (2013: 511) notes, "[t]he question of the nature of this relation is perhaps the deepest in all philosophy".

${ }^{20}$ See also Wilkenfeld (2013) and Hills (2015), both of whom argue that understanding involves a cognitive ability, e.g. to infer, explain, or mentally manipulate, which extends not just to actual circumstances but also to various counterfactual circumstances.

21 This may only extensionally distinguish the person who truly understands from the person who does not in this sort of case, but as I indicated above I would be satisfied with an extensionally correct account of grasping for the purposes of this paper.
} 
This seems to me to be a very natural way to conceive of the kind of understanding that is of relevance to the sciences. However, as noted above, I would also be happy to take $(\mathbf{U})$ as a stipulative definition of 'scientific understanding' for the purposes of this paper. So those who disagree with me about how to explicate the intuitive or commonly used concept of scientific understanding may still agree with everything else I say in this paper. Either way, what I will argue in the rest of this paper is this: Science makes (cognitive) progress precisely when scientists grasp how to correctly explain or predict more aspects of the natural world than they did before. This is the precise and canonical statement of the noetic account of scientific progress. Given $(\mathbf{U})$ - which may either be taken as an explication of the commonly used concept of understanding, or as a stipulation for how the term will be used in the remainder of the paper - this account can be described more succinctly as claiming that scientific progress consists in increasing understanding.

In order to see how the noetic account differs from the epistemic account, it is worth drawing out briefly how knowledge and understanding can come apart according to $(\mathbf{U})$. First of all, it is clearly possible to have a substantial amount of knowledge about something without understanding it. For example, I may know the length of a flagpole's shadow, the flagpole's height, the position of the sun, and the rectilinear propagation of light, and yet fail to grasp how to explain or predict the length of the flagpole's shadow, e.g. because I lack the relevant scientific or mathematical expertise or because I cannot be bothered to think through how such an explanation/prediction would proceed. In this respect, scientific understanding appears to be analogous to the kind of understanding one might have of an argument 
or proof, which requires a cognitive representation of how the conclusion follows from the premises that goes beyond knowing that the premises and conclusion are true. ${ }^{22}$

So, according to $(\mathrm{U})$, it is possible to have knowledge about something without understanding it. It is also possible to understand something according to $(\mathbf{U})$ without possessing knowledge of the relevant theories or propositions. To see why, note first of all that there is no requirement in $(\mathbf{U})$ that an agent has epistemic justification for the propositions on which her understanding is based. ${ }^{23}$ More precisely, an agent may partially understand something by virtue of grasping how to correctly explain or predict some aspect of it, even though she does not have the epistemic justification required for knowing the propositions to which she appeals in her explanations/predictions. (One might object that her grasp of how to correctly explain or predict would give her the required justification by some sort of explanatory inference, but as we shall see in the next section this is not necessarily the case.) Indeed, there is no requirement in $(\mathbf{U})$ to the effect that the agents believes that the relevant theories are true - she may merely assume or accept that they are true for the purposes of explanation and/or prediction. ${ }^{24}$ However, this latter way in which

\footnotetext{
${ }^{22}$ Note that it is also possible to know that some particular theory or theories can be used to correctly explain or predict aspects of a given target without having (partial) understanding of it. For example, I might come to know through reliable testimony that the length of the flagpole's shadow can be explained or predicted by the flagpole's height, the position of the sun, and the rectilinear propagation of light. Clearly, however, I would not thereby come to grasp how to correctly explain or predict the flagpole's shadow. Thus I would not even partially understand the flagpole's shadow according to $(\mathrm{U})$ (assuming I had no understanding of it beforehand).

${ }^{23}$ Nor is there any requirement that the agent not be in a Gettier-type situation that prevents a justified true belief from being knowledge.

${ }^{24} \mathrm{I}$ am using 'accept' here not in the sense of believing that a theory is empirically adequate - a sense often associated with van Fraassen's (1980) constructive empiricism - but in the sense of Jonathan Cohen's (1992) distinction between acceptance and belief. For Cohen, acceptance of a proposition is roughly a matter of treating the proposition as given in some particular context, e.g. in the context of explaining and predicting in science.
} 
understanding is possible without knowledge will play a much less prominent role in the arguments that follow. ${ }^{25}$

To sum up, I identify (partial) scientific understanding with a grasp of how to correctly explain and/or predict some aspects of the target in the right sort of circumstances. For someone to have understanding in this sense, having knowledge of the relevant propositions is neither necessary nor sufficient. Knowledge is not necessary for understanding because one can grasp how to correctly explain or predict something by appealing to epistemically unjustified theories (and by appealing to theories that one does not believe to be true). And knowledge is not sufficient for understanding because understanding involves a holistic cognitive state that goes beyond having knowledge of individual propositions. In what follows, I will exploit these differences between understanding and knowledge to argue that the understanding-based noetic account of scientific progress is superior to the knowledgebased epistemic account.

\section{Progress and Understanding without Knowledge}

Given the definition of understanding presented in the previous section, there are two kinds of cases in which increasing understanding and accumulation of knowledge can come apart. The first kind of case, to be discussed in this section, is one in which one's understanding of something increases even though no additional theories or phenomena become known in the process. In what follows I argue that the noetic

\footnotetext{
${ }^{25}$ See the end of section 5 for the only exception to this.
} 
account correctly counts these episodes as progressive, but that the epistemic account cannot do so without also counting clearly non-progressive episodes as progressive.

The class of cases that I will be concerned with have the following structure: Let $\mathrm{T}$ be some true theory that is, for lack of epistemic justification, not known by some scientist or group of scientists $\mathrm{S}$. Let $\mathrm{P}$ be some real phenomenon that is also not known by $\mathrm{S}$ to obtain or exist, for lack of epistemic justification. Now suppose $\mathrm{S}$ discovers how $\mathrm{T}$ explains and/or predicts $\mathrm{P}$ (or some aspects of $\mathrm{P}$ ). Since, by stipulation, $\mathrm{T}$ is true and $\mathrm{P}$ is real, $\mathrm{S}$ thereby gains additional understanding of $\mathrm{P}$. Thus the noetic account implies that there is scientific progress in cases of this sort. (As we shall see, this is clearly the correct verdict.) What about the epistemic account? Well, since $\mathrm{P}$ is itself unknown at the time of the discovery, the theory $\mathrm{T}$ that has been shown to explain and/or predict P need not have become known in the process. The same goes for $\mathrm{P}$ since $\mathrm{T}$ was unknown at the time of the discovery. So, in these cases, no new knowledge of either $\mathrm{T}$ or $\mathrm{P}$ is accumulated in the process of discovering how $\mathrm{T}$ explains and/or predicts $\mathrm{P}$. We can further stipulate that no other theories or phenomena became known during the episode in question - that the only change that occurred during the episode was S's discovery of how T explains and/or predicts P. If so, then the epistemic account appears forced to say that there would be no progress in cases of this sort. (We will soon see that things are a little more complicated, but not in a way that helps the epistemic account.)

As a case in point, consider Einstein's explanation of Brownian motion in terms of the kinetic theory of heat, presented in one of his famous annus mirabilis papers, "Investigations on the Theory of the Brownian Movement" (1905/1956). Einstein's first paragraph reads: 
In this paper it will be shown that according to the molecular-kinetic theory of heat, bodies of microscopically-visible size suspended in a liquid will perform movements of such magnitude that they can be easily observed in a microscope, on account of the molecular motions of heat. It is possible that the movements to be discussed here are identical with the so-called "Brownian molecular motion"; however, the information available to me regarding the latter is so lacking in precision, that I can form no judgment in the matter.

(Einstein 1905/1956: 1)

The hypothetical movements Einstein derived from the kinetic theory in the paper are indeed identical to the phenomenon known as 'Brownian motion', viz. the random motion of small but microscopically observable particles suspended in fluids. However, since Einstein's information about Brownian motion was lacking, Einstein clearly did not have the epistemic justification required to know that the movements in question were in fact real. Thus the explanandum in Einstein's explanation of Brownian motion did not constitute knowledge for Einstein at the time.

The same was arguably true of the explanans in 1905. The kinetic theory of heat was very much up for debate at the turn of the $20^{\text {th }}$ century, with many physicists favoring alternative theories of heat that did not assume the existence of submicroscopic molecules. Unless one adopts very relaxed standards for the kind of epistemic justification required for knowledge, Einstein will not count as having known the kinetic theory in 1905. At any rate, we can easily imagine a world in which Einstein's explanation was put forward before the kinetic theory of heat became sufficiently justified to be known (e.g. shortly after James Clerk Maxwell first presented his kinetic theory in 1859). In that case, certainly, neither the explanandum nor the explanans of Einstein's explanation would have been known at the time. None of this 
would take away from Einstein's achievement, which was to show how Brownian motion is explained by the kinetic theory of heat.

Now, it seems clear that Einstein's explanation of Brownian motion constituted significant (cognitive) progress in science. The noetic account explains why. On this account, Einstein made scientific progress because he enabled us to grasp how to correctly explain Brownian motion, thereby providing us with understanding of something that we were previously unable to understand. As I have set up the case, however, both the explaining theory and the explained phenomenon remained unknown (for lack of epistemic justification), and no additional theories or phenomena were introduced in the process. Thus, assuming the historical facts are as I have indicated (if not, we can imagine a nearby possible world in which they are) we appear to have here a case of scientific progress that is due to an increase in scientific understanding without any accumulation of scientific knowledge.

A proponent of the epistemic account may respond to this case by either (i) denying that Einstein's contribution really constitutes scientific progress, or (ii) insisting that Einstein's contribution reduces to an accumulation of scientific knowledge after all. ${ }^{26}$ Option (i) can be ruled out almost immediately, since Einstein's explanation of Brownian motion is widely considered to be one of the most significant

\footnotetext{
${ }^{26}$ Notice that the issue here does not depend on how one defines 'scientific understanding'. For example, suppose we agree (for the sake of the argument) with Bird's claim that "all (genuine as opposed to apparent) understanding is also knowledge. To understand why something occurred is to know what causes, processes, or laws brought it about." (Bird, 2007: 84) Adopting this conception of understanding won't help to defend the epistemic view against the current argument, since Einstein did not contribute to understanding in this sense. While Einstein's explanation certainly correctly identified the factors that produce Brownian motion, Einstein lacked the epistemic justification required for knowing what causes, processes, or laws bring it about. In short, the problem here is that if we define understanding so that it becomes a species of knowledge, as Bird would have us do, then Einstein's contribution can no longer be described as increasing understanding. As a consequence, Einstein's contribution would still not count as progressive on the epistemic account.
} 
achievements of one of history's greatest scientists. Denying that there is progress in this case is especially implausible for proponents of the epistemic account, who are committed to counting all instances of accumulated knowledge, however insignificant, as instances of scientific progress. So, to use a version of Bird's own example, gaining knowledge of the number of grains of sand on a beach between two points would count as progress on the epistemic account (Bird 2007: 84) ${ }^{27}$ If that counts as scientific progress on the epistemic account, then surely Einstein's correct explanation of Brownian motion in terms of the kinetic theory should also count as progress. It would be absurd to affirm that there is progress in the former case while denying that there is progress in the latter.

This leaves us with option (ii), i.e. insisting that Einstein's contribution to scientific progress reduces to an accumulation of knowledge. Since neither the explanans nor the explanandum of Einstein's explanation became known during the episode, there appears to be only one way in which Einstein's contribution can be seen as accumulating knowledge. That is, one might argue that Einstein's contribution to scientific progress consisted in gaining the knowledge that the kinetic theory would explain Brownian motion given that the kinetic theory is true and Einstein's description of Brownian motion is correct. On this suggestion, then, Einstein's achievement amounts to gaining a kind of hypothetical explanatory knowledge - knowledge of how a potential explanans would explain a potential explanandum if the explanans and

\footnotetext{
${ }^{27}$ To be fair, Bird later adds that the progress in question would be "slight and insignificant" (2007: 84). As I will discuss in section 4 (and as Bird acknowledges), this raises the issue of what makes some instances of progress less significant than others - an issue that remains unresolved by Bird. More importantly, even if the progress here is "slight and insignificant" it would still be greater than making no progress at all.
} 
explanandum are both true. Is this a plausible way of defending the epistemic account?

It is not. The problem is that hypothetical explanatory knowledge is far more common than genuine scientific progress. In fact, this is illustrated by an example that Bird (2007: 68-70) himself uses to argue against Laudan's (1977, 1984) problemsolving account of scientific progress. In the $14^{\text {th }}$ century, Nicole d'Oresme and many of his contemporaries believed that diamonds could be split with hot goat's blood. Now suppose Oresme had a radically false theory with which he managed to show why hot goat's blood would split diamonds (if the theory were true). In that case, Oresme would have shown how his theory would explain the splitting of diamonds using hot goat's blood given that his theory were true and diamonds could indeed be split in this way. So Oresme would have had hypothetical explanatory knowledge of the same kind as the response we are now considering attributes to Einstein. Thus, if the epistemic account says that the scientific progress made by Einstein's contribution was due to hypothetical explanatory knowledge, then it would also have to count as progressive Oresme's 'explanation' of why hot goat's blood would split diamonds.

Interestingly, Bird explicitly rejects this in the course of arguing against the problem-solving account of scientific progress:

While such a solution [to the problem of why hot goat's blood would split diamonds] might reasonably have seemed to Oresme and his contemporaries to be a contribution to progress it is surely mistaken to think that this is therefore a contribution to progress. Indeed, given that the solution would involve a falsehood as much as the problem itself Oresme's alleged progress adds falsity to falsity. (Bird, 2007: 69) 
I agree: Oresme's solution to the problem of why hot goat's blood would split diamonds does not constitute scientific progress. But then, I add, Einstein's contribution to scientific progress when explaining Brownian motion cannot be due to Einstein accumulating hypothetical explanatory knowledge, since that kind of knowledge would have been obtained by Oresme as well.

The crucial difference between Einstein and Oresme is of course that Einstein correctly explained a real phenomenon, while Oresme only provided an apparent explanation of an imaginary phenomenon. For this reason, Einstein's explanation of Brownian motion increased our understanding of the natural world, while Oresme's solution to the alleged problem of why hot goat's blood would split diamonds did not. Accordingly, on the noetic account of scientific progress, Einstein's explanation constitutes progress while Oresme's 'explanation' does not. This is surely the correct verdict. The epistemic account, by contrast, faces a crippling dilemma: If hypothetical explanatory knowledge does not constitute scientific progress on the epistemic account, then the account implies that Einstein did not contribute to scientific progress. If, however, hypothetical explanatory knowledge does constitute scientific progress on the epistemic account, then the account implies that Oresme contributed to scientific progress. Neither option is at all plausible.

\section{Progress and Knowledge without Understanding}

In the previous section I showed that there are scientifically progressive episodes in which scientific understanding increases while no knowledge of theories or phenomena is accumulated. In this section I show that there are non-progressive episodes in which knowledge of theories or phenomena is accumulated while there is 
no increase in scientific understanding. These cases provide further support for my thesis that scientific progress is made when understanding increases as opposed to when knowledge accumulates. To be sure, I do not hold that accumulations of knowledge that do not increase understanding are necessarily scientifically irrelevant or unimportant. Indeed, as we shall see, I grant that such accumulations may well promote scientific progress. I will argue, however, that accumulations of knowledge which fail to increase understanding cannot constitute scientific progress. But before I present the argument for this, let me mention a related consideration that also counts in favor of the noetic account over its epistemic counterpart.

As Bird himself acknowledges, "[i]t is plausible to hold that that those additions to knowledge that are also instances of understanding are, other things being equal, more significant [contributions to scientific progress] than those that are not." (2007: 84) Bird illustrates by considering the following example (mentioned briefly in the previous section):

[...] imagine a team of researchers engaged in the process of counting, measuring, and classifying geologically the billions of grains of sand on a beach between two points. Grant that this may add to scientific knowledge. But it does not add much to understanding. Correspondingly it adds little to scientific progress. (Bird 2007: 84)

Bird goes on to concede that the rate of progress in this example matches the rate of increased understanding, not the rate of accumulated knowledge. Of course, it is hard to see how one could measure increases in knowledge, understanding, and progress. Nevertheless, it does seem pre-theoretically plausible that there is a discrepancy between the rate of increased understanding and the rate of accumulated knowledge 
in this case, and that intuitively the rate of scientific progress matches the former rather than the latter.

Bird does not think that the grains-of-sand case counts against the epistemic account, since he claims that the epistemic account "says nothing about the rate of progress" (2007: 84). However, since the rate of progress does not match the amount of accumulated knowledge, this means that some additional account would have to be proposed to explain the rate of progress here and elsewhere, ${ }^{28}$ thus complicating the otherwise simple and straightforward epistemic account of scientific progress. By contrast, notice that the noetic account explains the low rate of progress by appeal to the fact that, intuitively, investigations of grains of sand provide very little understanding of the world around us. They may enable us to grasp how to correctly explain or predict some aspects of the beach, but this understanding would not extend to other parts of the world or give us deep insight into the nature of something in the way that understanding typically does. So, while investigating grains of sand may provide some understanding of the beach, it clearly won't give us anything like the amount of understanding provided by paradigmatic examples of scientific progress. In contrast to the epistemic account, the noetic account therefore neatly explains why some instances of scientific progress are more significant than others without adding any further complications to the account. This seems to me to be a weighty consideration in favor of the noetic account.

I won't dwell on this point, however, since there is a related but more clear-cut case against the epistemic account and in favor of the noetic account. In brief, the argument is that in cases where science sees an accumulation of knowledge without

\footnotetext{
${ }^{28}$ Bird explicitly acknowledges this (2007: 84).
} 
also seeing an increase in scientific understanding, there does not seem to be any scientific progress. The hardest part of making this argument is finding cases in which knowledge accumulates without any increase in scientific understanding. Such cases are admittedly rare, since most accumulations of knowledge (and, indeed, of true belief) will contribute at least a little bit to understanding in virtue of enabling us to correctly explain or predict some aspect of the natural world. Indeed, as we have noted, even classifications of the grains of sand on a beach may help us along a little bit in this regard. Nevertheless, there are at least three categories of cases in which knowledge is accumulated without any corresponding increase in scientific understanding.

The first category of such cases concerns random experimental outcomes. Suppose there is an experimental setup that is known on independent grounds to randomly produce one of outcomes $\mathrm{O}_{1}$ through $\mathrm{O}_{\mathrm{n}}$ on a given occasion. Let us further suppose that there is nothing strange going on so that each time we observe some outcome $\mathrm{O}_{\mathrm{i}}$ we come to know that $\mathrm{O}_{\mathrm{i}}$ did in fact obtain in that instance. However, since the outcome would by stipulation be known to be completely random, this additional piece of knowledge would not enable us to predict any additional aspect of the world. It would not provide any explanatory insight either, since we knew already that the outcome would be random, and the fact that $\mathrm{O}_{\mathrm{i}}$ was the outcome in a particular instance provides no insight into the workings of the experimental setup. Thus, we have that learning that $\mathrm{O}_{\mathrm{i}}$ obtains provides no understanding whatsoever, and yet it gives us an additional piece of knowledge - viz. the trivial knowledge that $\mathrm{O}_{\mathrm{i}}$ obtained in this instance. Intuitively, this is not a case of scientific progress.

Another category of cases concerns spurious statistical correlations. Suppose we have two variables $V_{1}$ and $V_{2}$ that are known on independent grounds to be 
unrelated, causally and nomologically. Let us further suppose that we learn, i.e. come to know, that there is some specific statistical correlation between $V_{1}$ and $V_{2}-$ e.g. such that a greater value for $\mathrm{V}_{1}$ is correlated with a greater value for $\mathrm{V}_{2}$. There are many real cases of this kind. For example, it happens to be true that there is a strong correlation between increases in childbirth rates outside of Berlin city hospitals and increases in stork populations around the city. When this piece of information was published in a recent satirical journal article that warned against coincidental statistical associations (Höfer et al. 2004), ${ }^{29}$ there was an accumulation of knowledge that would have to count as scientific progress on the epistemic account. However, this information provides no understanding since it does not enable us to correctly explain or predict any aspect of childbirth rates or stork populations (or indeed any other relevant phenomenon). Intuitively, this is not a case of scientific progress.

A final category of cases concerns severely impoverished observational reports. Suppose a group of very inexperienced scientists are tasked with observing a class of discrete objects, e.g. the seagulls around New York City. Lacking training and further instructions, the scientists go out in different numbers each day to make their observations without registering where they went or how many scientists went on each trip. Worse still, they record only the time and date at which a seagull is observed. Thus their entire observational record consists of a list where each entry has the following form: "Seagull observed at [time] on [date]." Let us suppose that they did this very carefully and meticulously for a long period of time, so that the list constitutes a large number of known propositions. However, this list clearly does not underwrite

\footnotetext{
${ }^{29}$ The article, entitled "New Evidence for the Theory of the Stork", came with a disclaimer warning against the methods used in the paper and clarifying that the paper should be read as "a humorous case study for education in perinatal epidemiology.” (Höfer et al. 2004: 88)
} 
any explanations regarding the seagulls around New York City, nor does it enable correct predictions to be made on its basis. Thus we have that the scientists accumulated a considerable amount of knowledge, even though there was no increase in scientific understanding. Intuitively, there is no progress in this case.

How might a proponent of the epistemic account respond to these cases? There are two options here. First, she might try to deny that there is accumulation of knowledge here. This response strikes me as hopeless. As I have described the cases, they involve discoveries of true propositions, and by stipulation there is nothing epistemically defective about the ways in which these truths were discovered. For example, the problem with the correlation between childbirth rates and stork population sizes is not that it fails to be true, believed, justified, or non-Gettiered (or that it fails to satisfy any other condition that might be required for knowledge), but that the correlation in question is useless for understanding the natural world. What makes these cases intuitively non-progressive has nothing to do with their epistemic merits, and everything to do with whether they can be used in particular ways in order to correctly explain or predict aspects of the natural world. ${ }^{30}$

The other way to respond to the three categories of cases described above would be to reject the intuitions and insist that there would be some (perhaps very modest) scientific progress in these cases. I offer two replies: First, this does not seem remotely plausible unless one has in mind some extremely watered-down notion of scientific progress on which scientists are virtually constantly making progress. I do not

\footnotetext{
${ }^{30}$ Notice also that it won't help to stipulate that only accumulations of scientific knowledge constitute progress, since all three categories of cases involve knowledge of the sort that is routinely obtained in science, viz. experimental, correlational, and observational knowledge. Thus, even if it were possible to distinguish between 'scientific' and 'non-scientific' knowledge - which is highly doubtful - the types of knowledge discussed above would surely count as scientific.
} 
think that this is the notion of progress that participants in the debate have thus far been interested in. In particular, Bird is quite clear that achieving progress should not be "too easy". (2007: 83) Indeed, it is worth noting that watering-down the notion of scientific progress that is being explicated in this way would be an especially strange response for a proponent of the epistemic account, since she is committed to it being impossible to achieve progress without accumulation of full-blown knowledge. This means that true scientific theories for which we presently lack epistemic justification or for which we are in a Gettier-situation would not count as progressive on the epistemic account, no matter how much understanding such theories would provide.

Second, and more importantly, insisting that there is scientific progress in these three examples conflicts with overwhelmingly plausible ideas about what makes for a well organized scientific practice. It is a platitude that, other things being equal, scientific practice should be organized around the achievement of scientific progress. Thus, if one allows that science can make progress by accumulating trivial pieces of knowledge of the sort described in the three cases above, then one must say that a scientific practice that is designed to accumulate trivial knowledge of this sort would, other things being equal, be well-organized. However, a scientific practice organized around accumulating trivial knowledge of this kind would seem to be a paradigm example of degenerate science. Note, for example, that no self-respecting scientific journal would publish results of this kind, except as a parody. ${ }^{31}$ Similarly, research proposals outlining investigations of these sorts would not be taken seriously by any scientific funding agency. ${ }^{32}$

\footnotetext{
${ }^{31}$ As in (Höfer et al. 2004). (See footnote 22.)

${ }^{32}$ A proponent of the epistemic account might respond to the objection presented in this paragraph by insisting that gaining trivial pieces of knowledge would only count as very little progress on the
} 
Of course, a proponent of the epistemic account could respond to the three categories of cases described above by conceding that not all episodes in which knowledge is accumulated should count as progressive and modify her account accordingly. This is a sensible response, but not one that can be evaluated until we are told how the epistemic account will be modified. If it is stipulated that the relevant kind of knowledge must help us correctly explain or predict some aspect of the world which is the modification that seems to be required to avoid these examples of trivial knowledge counting as progressive - then this amounts to conceding that science only makes progress when scientific understanding increases. That, however, is precisely what I am arguing in this section. Of course, there would still be a difference between the noetic account and the modified epistemic account, since the former would not require that our understanding be based on known propositions. But then I have argued in the previous section that this is not required for progress, so this modified epistemic account would still be inadequate.

This concludes my argument that the noetic account of scientific progress is superior to the epistemic account in virtue of discounting as non-progressive various cases in which scientific knowledge is accumulated but scientific understanding does not increase. Relatedly, this section has also argued that in contrast to the epistemic account, the noetic account effortlessly explains why certain episodes seem to involve

epistemic account. Thus, since more progress could be obtained by focusing on non-trivial knowledge, a scientific practice organized around accumulating trivial knowledge would not be optimal. I have two replies: First, note that in order for this response to work, the epistemic account must be supplemented with an account of how much progress is contributed by each kind of knowledge, and no such account is forthcoming. Second, and more importantly, this response does not fully deal with the problem since it still allows that there are cases in which the progress provided by the accumulation of non-trivial knowledge would be greater than the progress provided by the accumulation of a sufficiently large amount of trivial knowledge that could be obtained just as easily, in which case an optimal scientific practice would be organized around gaining the large amount of trivial knowledge. This consequence of the (modified) epistemic account is still clearly unacceptable. 
very little progress even though a significant amount of knowledge is accumulated. Together with the argument of the previous section, these points already constitute a strong case for the noetic account over its epistemic counterpart. To further strengthen this case, I will now consider two objections on behalf of the epistemic account - one of which argues that increased understanding is not necessary for progress; the other that increased understanding is not sufficient for progress.

\section{Objections and Replies}

Objection 1: Not all discoveries that fail to increase understanding are examples of trivial pieces of knowledge like those discussed in the previous section. In particular, a scientist may collect some raw data that gives her no additional understanding at present, e.g. because there simply is not enough data to indicate how to correctly explain or predict anything on that basis. While collecting such raw data may not revolutionize science, it is surely quite valuable in many cases. Indeed, since collecting data is itself essential to achieving scientific understanding at a later point, it can be described as 'a step in the right direction'. So why not count such episodes in which raw data is collected as scientifically progressive?

Reply: I agree that collecting raw data that does not by itself increase understanding is often valuable for the achievement of scientific progress, but I resist the implication that collecting such data should count as scientific progress. As noted in section 1, it is possible for something to promote scientific progress without constituting such progress. Accordingly, I would characterize the collection of data that does not by itself enable us to explain or predict anything (but puts us in a position to do so in the future) as promoting rather than constituting scientific progress. Clearly, 
promoting scientific progress is valuable for the purposes of scientific progress. Thus, on my view, collecting raw data is often valuable for the purposes of achieving scientific progress even when this does not by itself constitute scientific progress.

Having said this, I would not much mind if the noetic account were modified so as to allow data-collection of this kind to count as scientifically progressive. Suppose we said that science makes progress just in case it either increases, or promotes the increase of, scientific understanding. On this modified noetic account, collecting raw data would count as progressive as long as it promotes an increase in scientific understanding. My reason for preferring the simpler account on which science makes progress precisely when there is increased scientific understanding is that is that it seems to make perfect sense to say that something promotes progress. However, if promoting increased understanding is itself a kind of scientific progress, then promoting scientific progress may amount to promoting the promotion of increased understanding. I prefer to avoid this conceptually awkward situation by keeping the concept of promotion distinct from the concept of progress. Those who disagree and prefer to modify the noetic account such that the promotion of increased understanding counts as a kind of progress are welcome to do so.

Objection 2: In stark contrast to my argument in section 3, Bird (2007: 65-67) argues directly that epistemic justification is necessary for scientific progress. Bird's argument is that, intuitively, the accumulation of true but unjustified beliefs does not constitute scientific progress. For example, the French scientist Réné Blondlot appears to have believed in the existence of what he called 'N-rays' (analogous to X-rays) without having any real evidence for his theory other than subjective observations (which were known to be highly unreliable in the circumstances). If we now suppose that there are in fact such things as N-rays, Bird claims that it nevertheless seems 
intuitively wrong to attribute scientific progress to Blondlot's discovery. Bird concludes from this that accumulating true or truthlike beliefs is not sufficient for progress because such beliefs may fail to be justified. Since I do not take justification to be required for understanding, the same argument would seem to apply to my understanding-based noetic account of scientific progress.

Reply: Bird's argument has been criticized on various grounds by Cevolani and Tambolo (2013), Niiniluoto (2014), and Rowbottom (2008, 2010, 2015). While I think that these criticisms are on the right track, I'll develop my own response in a different way. Since Bird's argument rests on an intuition about when scientific progress is made, I will start by clarifying what the relevant intuition would have to be for Bird's argument to succeed against the noetic account. I then go on to suggest that this intuition ought to be rejected. I will also argue that the intuition in question only appears plausible if one confuses scientific progress tout court with scientific progress achieved by epistemically agreeable means.

In order for Blondlot's discovery to constitute progress in Bird's example, Blondlot's theory of N-rays (which are assumed to exist in this scenario) would have to have been sufficiently true to the actual facts to enable Blondlot to correctly explain or predict some real phenomena with the theory. Since N-rays do not in fact exist, it is somewhat difficult to imagine what the corresponding explanations and predictions would be, but note that they would have to be correct. So let's suppose, for example, that Blondlot's N-ray theory offered a correct explanation of why some materials emit light of a certain wavelength when heated to a specific point. In that case, is it so obvious that Blondlot's discovery (which was a discovery in this fictional case) is intuitively not a case of scientific progress? Granted that Blondlot would be behaving in an epistemically objectionable manner if he believed his theory on the basis of 
insufficient evidence (a point to which we will return), I see no reason why we should conclude that Blondlot would not have contributed to scientific progress in this fictional case. ${ }^{33}$

To bolster this response, let me emphasize that the N-ray example is a piece of historical fiction. In reality, Blondlot's N-ray theory does not provide us with scientific understanding since there are no such things as N-rays. Let us therefore consider a more realistic case in which a true theory is used as the basis for explanations and/or predictions even though scientists lacked the epistemic justification required for knowing that the theory is true. For example, Bird (2007: 67) claims that Alfred Wegener's theory of continental drift was not supported by sufficient evidence for the theory to be known until long after Wegener first proposed it in 1910. So, according to Bird's epistemic account, Wegener's theory would not have constituted progress even if it had it become accepted at the time. On the noetic account, however, acceptance of Wegener's theory would have constituted progress since it would have enabled scientists to grasp how to correctly explain various aspects of the Earth's geological history and perhaps even predict its future trajectory. In this more realistic case, it seems to me that intuition is decisively on the side of the noetic account.

So I reject the alleged intuitions that are meant to support the claim that epistemic justification is required for scientific progress. When the fictional N-ray example has been properly specified so as to make clear that the discovery increases scientific understanding, I submit that it is a case of scientific progress. This is even clearer in the case of Wegener's theory of continental drift, where there would clearly

\footnotetext{
${ }^{3}$ As Rowbottom (2015: 103) points out, a recent empirical survey soliciting folk intuitions about scientific progress (Mizrahi and Buckwalter 2014) does not support Bird's premise that, intuitively, justification is necessary for progress.
} 
be progress even though the epistemic justification for the theory is (by Bird's own lights) not sufficient for knowledge. That being said, I do concede that there is something amiss in both cases, which may ultimately be responsible for why Bird's argument has some initial appeal. I will therefore supplement my response to Bird's argument by outlining an error-theoretic explanation for Bird's intuition that scientific progress cannot be made in the absence of epistemic justification.

I start with the observation that Blondlot's discovery would have involved epistemically objectionable behavior. Now, it is certainly understandable that we would hesitate to attribute progress in cases of that sort, just as we might hesitate to attribute progress in any other case where progress towards some end is made by means of which we disapprove. For example, consider an athlete that makes progress towards her goal of running 100 meters in less than 10 seconds by using performanceenhancing drugs that permanently improve her best time by a whole second. Does such an athlete make progress towards her goal of running 100 meters in 10 seconds? Upon reflection, the answer is clearly 'yes', since she would indeed run the 100 meters faster than before. However, we might initially hesitate to attribute progress to this athlete because we disapprove of the manner in which progress was made. The key point here is that we hold athletes to certain standards, and it may initially seem paradoxical that a given athlete can be said to have made progress when she fails to live up to those standards.

Analogously, we hold each other (and especially scientists) to certain standards of epistemic justification. In particular, we disapprove of those who form beliefs on the basis of insufficient evidence, even when those beliefs turn out to be true. We therefore rightly disapprove of Blondlot's stubborn belief that there are N-rays, formed as it was on the basis of dubious evidence. This means that Blondlot's discovery is not 
praiseworthy in the same way as most other episodes of scientific progress. But to conclude that Blondlot's discovery in the fictional case did not constitute progress at all is to confuse scientific progress tout court with scientific progress made by epistemically agreeable means. While there are good reasons to disapprove of the practices that led to Blondlot's discovery, it does not follow that this (fictional) episode should not be counted as progressive at all. Similarly, while we may prefer for Wegener to have refrained from believing the theory of continental drift until more conclusive evidence had been obtained, it does not follow that Wegener's discovery in 1910 should not be regarded as progressive in that case. Rather, it is most natural to describe Wegener's contribution as an instance of scientific progress made on the basis of somewhat insufficient or incomplete evidence.

This error-theoretic explanation for the initial appeal of Bird's intuition also explains why we don't have a similar reaction in the case of Einstein's explanation of Brownian motion. In Einstein's case, there is nothing to suggest that Einstein himself formed any belief based on insufficient evidence because there is no reason to think that Einstein had any firm beliefs about either the kinetic theory or his derived description of Brownian motion. Einstein simply never commits to either the kinetic theory or to any particular description of Brownian motion in his 1905 paper. What he did was to show how to explain Brownian motion with the kinetic theory, and for this purpose there was no need to affirm or deny either the explaining theory or the explained phenomenon. So my error-theoretic explanation of the initial appeal of Bird's argument correctly implies that we should be less hesitant to attribute progress to Einstein's achievement than to Blondlot's discovery in Bird's fictional case. 


\section{Further Advantages}

So far I have argued that cases in which knowledge and understanding come apart in science indicate that scientific progress matches increases in scientific understanding rather than accumulations of scientific knowledge. These cases provide a straightforward case for the noetic account over its epistemic counterpart, but there are other advantages of the noetic account as well. In this final section, I will suggest that the noetic account is better equipped to deal with considerations having to do with minimalist idealizations, pragmatic virtues, and epistemic value. To be clear, none of these considerations are meant to constitute conclusive arguments against the epistemic account. In each case, there are ways for the proponent of the epistemic account to reply or modify her position so as to avoid the problem in question - ways that I lack space to explore here. However, the ease with which the noetic account deals with these problems further suggests that the noetic account is an improvement on the epistemic account.

The first additional advantage of the noetic account over the epistemic account concerns the role of idealizations in scientific explanations. In particular, consider the kind of idealizations that Michael Weisberg (2007: 642-645) calls minimalist idealizations. A minimalist idealization is a model that contains the core causal claims that make a difference to a given phenomenon under investigation, but also eliminates or exaggerates explanatorily irrelevant factors in order to illuminate aspects of reality that would otherwise be obscured by their complexity. Consider, for example, the fact that many current population models in evolutionary biology (e.g. the Hardy-Weinberg Law) assume that populations are infinitely large in their explanations of biological phenomena such as the fixation of phenotypic traits. Since the purpose of minimalist idealization is to facilitate scientific explanation by isolating 
explanatorily relevant factors, such idealizations may be useful even then more accurate, non-idealized theories are available. As Weisberg notes, this means that unlike some other kinds of idealizations, "minimalist idealization is not at all pragmatic and we should not expect it to abate with the progress of science." (Weisberg, 2007: 645)

By definition, minimalist idealizations are not true. However, as noted above ${ }^{34}$ this does not mean that explanations based on minimalist idealizations are not correct. As long as such minimalist idealizations help identify the factors that are explanatorily relevant to the explained phenomenon, they have the kind of accuracy required for the associated explanations to undergird scientific understanding. So the noetic account (correctly) implies that scientific progress can be made by generating new minimalist idealizations (and, relatedly, that abandoning such idealizations may regress science) even when non-idealized versions of these theories are available. By contrast, since idealized theories are not true, the epistemic account (incorrectly) implies that no progress is made when one generates minimalist idealizations, at least not when more accurate, non-idealized theories are available. Relatedly, the epistemic account also (incorrectly) implies that minimalist idealizations ought to abate as science progresses, since there would be no point in having idealized theories from a purely epistemic point of view when non-idealized versions of these theories have been made available.

A related advantage of the noetic account concerns pragmatic virtues. By 'pragmatic virtues' I am referring to features of a theory that are not presumed to make the theory any likelier to be true, but instead make the theory easier to

\footnotetext{
${ }^{34}$ See section 2.
} 
conceptualize or utilize for some purposes. Arguably, the simplicity with which a theory is formulated (theoretical simplicity) is a pragmatic virtue in this sense, at least when distinguished from parsimony in the number of entities or causes postulated by the theory (ontological simplicity). Now, suppose we have a choice between accepting one of two equivalent theories, $\mathrm{T}_{1}$ and $\mathrm{T}_{2}$, which differ only in the way the theories are formulated, e.g. in that $T_{1}$ has greater theoretical simplicity than $T_{2}$. Scientific practice (and common sense) suggests that $\mathrm{T}_{1}$ should be preferred to $\mathrm{T}_{2}$. But why? Given that $T_{1}$ and $T_{2}$ are equivalent, why should one accept the simpler $T_{1}$ rather than the more complex $\mathrm{T}_{2}$ ?

On the noetic account, the answer is straightforward. A simple theory enables us to explain and predict aspects of the world that would be more difficult or even impossible to explain and predict with a more complex theory. So, even though $\mathrm{T}_{1}$ and $T_{2}$ are equivalent, the simpler $T_{1}$ would provide us with more understanding than the more complex $\mathrm{T}_{2}$, and thus make a greater contribution to scientific progress. By contrast, the epistemic account implies that the progress contributed by each theory is exactly the same. After all, the propositional content of the two theories is identical, so the amount of knowledge gained by coming to know $T_{1}$ is (by any measure) exactly the same as the amount of knowledge gained by coming to know $\mathrm{T}_{2}$. Thus, in contrast to the noetic account, the epistemic account does not account for the scientific preference for theories that possess pragmatic virtues such as theoretical simplicity.

A third and final advantage of the noetic account over the epistemic account concerns the relationship between epistemic value and scientific progress. In recent years, a number of epistemologists have come to question the idea that knowledge has any distinctive epistemic value (see, e.g., Kaplan 1985; Kvanvig 2003, 2009; Pritchard 2009, 2010; BonJour 2010). In brief, the problem - first discussed in Plato's Meno and 
thus often known as 'the Meno Problem' - is that it is unclear why knowledge is more valuable than weaker epistemic standings such as true and/or justified belief. Discussions of this problem often point out that there is no similar problem about how to account for the distinctive value of understanding, which suggests that understanding is a more valuable epistemic standing than knowledge. Indeed, partly for this reason, it has been argued that understanding should replace knowledge as the primary focus of epistemological theorizing (see, e.g., Zagzebski 2001; Kvanvig 2003, 2009; Elgin 2006; Pritchard 2009, 2010; see also Grimm 2012).

If understanding but not knowledge is distinctively valuable, as the recent literature on the Meno Problem suggests, then this provides a further consideration in favor of the noetic account over the epistemic account. To see why, recall that the epistemic and noetic accounts translate into distinct theses about the aim of science, viz. the theses that that science aims for knowledge and understanding respectively. ${ }^{35}$ Now, if knowledge has no distinctive value, then it is unclear why science (or any other cognitive enterprise) should be aiming for knowledge as opposed to the weaker epistemic standing that is distinctively valuable. So the Meno Problem is a problem for a knowledge-based view of the aim of science, and thus by implication also a problem for the epistemic account of scientific progress. By contrast, since there is no similar problem about the distinctive value of understanding, there is no difficulty involved in explaining why science would aim to achieve understanding. In sum, then, the Meno Problem for knowledge and the lack of a corresponding problem for understanding constitutes a further reason to favor the noetic account over its epistemic counterpart.

\footnotetext{
35 See section 1 .
} 


\section{Conclusion}

The idea that science makes progress by accumulating knowledge is prima facie plausible. However, the initial appeal of this idea may be due to the fact that knowledge has not always been clearly distinguished from understanding. When we take care to distinguish these two cognitive states, it starts to seem less obvious that knowledge rather than understanding is what increases when science makes cognitive progress. In order to settle this issue, I have considered cases in which knowledge and understanding come apart. It has been shown that in these cases, scientific progress follows increases in scientific understanding rather than accumulations of knowledge. In addition, I have argued that considerations having to do with minimalist idealizations, pragmatic virtues, and epistemic value all favor the understanding-based noetic account of scientific progress over the knowledge-based epistemic account. 


\section{References}

Bacon, F. (1620/1900). Novum Organum. Translated by R. Ellis and J. Spedding. London: Routledge.

Bangu, S. (2015). "Progress, Understanding, and Unification", in I. D. Toader, G. Sandu \& I. Pârvu (eds.), Romanian Studies in Philosophy of Science. Cham: Springer.

Barnes, E. (1991). "Beyond Verisimilitude: A Linguistically Invariant Basis for Scientific Progress", Synthese 88: 309-339.

Bird, A. (2007). "What is Scientific Progress?", Noûs 41: 64-89.

Bird, A. (2008). "Scientific progress as accumulation of knowledge: A reply to Rowbottom", Studies in History and Philosophy of Science 39: 279-281.

Bird, A. (forthcoming). "Scientific Progress", in P. Humphreys (ed.), Oxford Handbook in Philosophy of Science (Oxford: Oxford University Press).

Bragg, W. (1936). "The Progress of Physical Science", in J. Jeans et al., Scientific Progress (London: George Allen and Unwin), pp. 39-78.

Brogaard, B. (2005). "I Know. Therefore, I Understand”, unpublished typescript.

BonJour, L. (2010), “The Myth of Knowledge", Philosophical Perspectives 24: 57-83.

Cevolani, G., and Tambolo, L. (2013). "Progress as Approximation to the Truth: A Defence of the Verisimilitudinarian Approach", Erkenntnis 78: 921-935.

Cohen, L. J. (1980). “What Has Science to Do with Truth?”, Synthese 45: 489-510.

Cohen, L. J. (1992). An Essay on Belief and Acceptance. Oxford: Oxford University Press.

Douglas, H. (2009). "Reintroducing Prediction to Explanation", Philosophy of Science 76: 444-463. 
Einstein, A. (1905/1956). Investigations on the Theory of the Brownian Movement. Translated by A. D. Cowper. New York: Dover.

Elgin, G. (2006). "From Knowledge to Understanding", in S. Hetherington (ed.), Epistemology Futures (Oxford: Oxford University Press), pp. 199-215.

Elgin. C. (2007). "Understanding and the Facts", Philosophical Studies 132: 33-42.

Elgin, C. (2009a). "Exemplification, Idealization, and Understanding”, in M. Suárez (ed.), Fictions in Science: Essays on Idealization and Modeling (London: Routledge), pp. 77-90.

Elgin, C. (2009b). "Is Understanding Factive?", in A. Haddock, A. Millar, and D. Pritchard (eds.) Epistemic Value (New York: Oxford University Press), pp. 322330.

Finocchiaro, M. (1975). "Cause, Explanation, and Understanding in Science: Galileo's Case", Review of Metaphysics 29: 117-128.

Finocchiaro, M. (1976). "Scientific Discoveries as Growth of Understanding: The Case of Newton's Gravitation”, in T. Nickles (ed.), Scientific Discovery, Logic, and Rationality (Dordrecht: D. Reidel Publishing Company), pp. 235-255.

Friedman, M. (1974). "Explanation and Scientific Understanding", fournal of Philosophy 71: 5-19.

Gijsbers, V. (2007). "Why Unification is Neither Necessary Nor Sufficient for Explanation", Philosophy of Science 74: 481-500.

Gijsbers, V. (2013). "Understanding, explanation, and unification”, Studies in History and Philosophy of Science 44: 516-522. 
Grimm, S. (2006). "Is Understanding a Species of Knowledge?”, British Fournal for the Philosophy of Science 57: 515-35.

Grimm, S. (2011). "Understanding", in S. Bernecker and D. Pritchard (eds.), The Routledge Companion to Epistemology (London: Routledge), pp. 84-94.

Grimm, S. (2012). "The Value of Understanding", Philosophy Compass 7: 103-117.

Grimm, S. (2014). "Understanding as Knowledge of Causes", in A. Fairweather (ed.), Virtue Epistemology Naturalized: Bridges Between Virtue Epistemology and Philosophy of Science (Synthese Library, vol. 366). Cham: Springer, pp. 329-345.

Hempel, C. G., and Oppenheim, P. (1948). "Studies in the Logic of Scientific Explanation", Philosophy of Science 15: 135-175.

Hills, Alison (2015). “Understanding Why”, Noûs. DOI: 10.1111/nous.12092.

Höfer, T., Przyrembel, H., and Verleger, S. (2004). "New Evidence for the Theory of the Stork", Paediatric and Perinatal Epidemiology 18: 88-92.

Kaplan, M. (1985). "It's Not What You Know that Counts", Fournal of Philosophy 82: $350-63$.

Kelp, C. (forthcoming). "Understanding Phenomena”, Synthese.

Khalifa, K. (2013a). "Is Understanding Explanatory or Objectual?", Synthese 190: $1153-1171$.

Khalifa, K. (2013b). "The Role of Explanation in Understanding", British fournal for the Philosophy of Science 64: 161-187.

Khalifa, K. (2013c). "Understanding, Grasping, and Luck”, Episteme 10: 1-17.

Kitcher, P. (1981). “Explanatory Unification”, Philosophy of Science 48: 507-531. 
Kitcher, P. (1989). "Explanatory Unification and the Causal Structure of the World", in P. Kitcher and W. C. Salmon, Scientific Explanation (Minneapolis: University of Minnesota Press), pp. 410-505.

Kitcher, P. (2002). "Scientific Knowledge", in P. Moser (ed.), The Oxford Handbook of Epistemology (New York: Oxford University Press), pp. 385-408.

Kuhn, T. S. (1970). The Structure of Scientific Revolutions, $2^{\text {nd }}$ edition. Chicago: University of Chicago Press.

Kvanvig, J. (2003). The Value of Knowledge and the Pursuit of Understanding. New York: Cambridge University Press.

Kvanvig, J. (2009). "The Value of Understanding", in A. Haddock, A. Millar, and D. Pritchard (eds.), Epistemic Value (New York: Oxford University Press), pp. 95111.

Laudan, L. (1977). Progress and Its Problems. London: Routledge and Kegan Paul.

Laudan, L. (1984). Science and Values. Berkeley: University of California Press.

Lipton, P. (2004). Inference to the Best Explanation, $2^{\text {nd }}$ edition. London: Routledge.

Lipton, P. (2009). "Understanding without Explanation”, in H. de Regt, S. Leonelli, and K. Eigner (eds.), Scientific Understanding: Philosophical Perspectives (Pittsburgh: University of Pittsburgh Press), pp. 43-63.

Mizrahi, M. (2012). "Idealizations and Scientific Understanding”, Philosophical Studies 160: 237-252.

Mizrahi, M. and Buckwalter, W. (2014). "The role of justification in the ordinary concept of scientific progress", Journal for General Philosophy of Science 45: 151166. 
Niiniluoto, I. (1980). "Scientific Progress", Synthese 45: 427-462. Reprinted in Niiniluoto (1984).

Niiniluoto, I. (1984). Is Science Progressive? Dordrecht: Reidel.

Niiniluoto, I. (2014). "Scientific Progress as Increasing Verisimilitude", Studies in History and Philosophy of Science 46: 73-77.

Niiniluoto, I. (2015). "Scientific Progress", in E. N. Zalta (ed.), The Stanford Encyclopedia of Philosophy (Summer 2015 Edition).

Pritchard, D. (2009). "Knowledge, Understanding, and Epistemic Value", in A. O’Hear, Epistemology (New York: Cambridge University Press), pp. 19-43.

Pritchard, D. (2010). "Knowledge and Understanding", in A. Haddock, A. Millar, and D. Pritchard, The Nature and Value of Knowledge: Three Investigations (New York: Oxford University Press), pp. 3-90.

Riggs, W. D. (2009). "Understanding, Knowledge, and the Meno Requirement", in A. Haddock, A. Millar, and D. Pritchard (eds.), Epistemic Value (New York: Oxford University Press), pp. 331-338.

Rowbottom, D. P. (2008). "N-rays and the semantic view of scientific progress", Studies in History and Philosophy of Science 39: 277-278.

Rowbottom, D. P. (2010). "What Scientific Progress is Not: Against Bird's Epistemic View", International Studies in Philosophy of Science 24: 241-255.

Rowbottom, D. P. (2015). "Scientific progress without increasing verisimilitude: In response to Niiniluoto", Studies in History and Philosophy of Science 51: 100-104.

Sarton, G. (1927). Introduction to the History of Science, vol. I. Baltimore: Carnegie Institution of Washington. 
Salmon, W. G. (1984). Scientific Explanation and the Causal Structure of the World. Princeton: Princeton University Press.

Salmon, W. G. (1989). "Four Decades of Scientific Explanation", in P. Kitcher and W. G. Salmon, Scientific Explanation (Minneapolis: University of Minnesota Press), pp. 3-219.

Salmon, W.C. (1993). "The Value of Scientific Understanding”, Philosophica 51: 9-19.

Salmon, W. C. (1998). Causality and Explanation. Pittsburgh: University of Pittsburgh Press.

Schurz, G. (1999). "Explanation as Unification", Synthese 120: 95-114.

Schurz, G. and Lambert, K. (1994). "Outline of a Theory of Scientific Understanding”, Synthese 101: 65-120.

Scriven, M. (1962). "Explanation, Prediction, and Laws", in H. Feigl and G. Maxwell (eds.), Minnesota Studies in the Philosophy of Science, vol. 3 (Minneapolis: University of Minnesota Press), pp. 170-230.

Strevens, M. (2013). "No Understanding Without Explanation", Studies in History and Philosophy of Science 44: 510-515.

Van Fraassen, B. C. (1980). The Scientific Image. Oxford: Clarendon Press.

Weisberg, M. (2003). "Three Kinds of Idealizations", Fournal of Philosophy 104: 639-659

Wilkenfeld, D. (2013). "Understanding as Representation Manipulability", Synthese 190: 997-1016.

Zagzebski, L. (2001). "Recovering Understanding," in M. Steup (ed.), Knowledge, Truth, and Duty: Essays on Epistemic Justification, Responsibility, and Virtue (New York: Oxford University Press), pp. 235-252. 